\title{
Local acclimatisation-driven differential gene and protein expression patterns of Hsp70 in Acropora muricata: implications for coral resistance to bleaching
}

\author{
Yohan Louis ${ }^{1}$, Ranjeet Bhagooli ${ }^{2}$, Dacide Seveso ${ }^{3}$, Paolo Galli ${ }^{4}$, Marina Vai $^{5}$, and Sabrina \\ Dyall $^{2}$ \\ ${ }^{1}$ University of Mauritius \\ ${ }^{2}$ University of Mauritius Faculty of Science \\ ${ }^{3}$ University of Milano - Bicocca \\ ${ }^{4}$ University of Milan-Bicocca \\ ${ }^{5}$ University of Milan-Bicocca Department of Biotechnology and Biosciences
}

May 5, 2020

\begin{abstract}
Corals show spatial acclimatization to local environment conditions. The various cellular mechanisms involved in local acclimatization and variable bleaching patterns in corals remain to be thoroughly investigated. In this study, the modulation of a protein involved in cellular heat stress tolerance, the Heat shock protein 70 (Hsp70), was compared at both gene expression and protein level in Acropora muricata colonies from two contrasting environments, in the lagoonal system of Belle Mare (Mauritius), having differential bleaching susceptibilities. The relative Hsp70 levels varied significantly between colonies from the different environments, colonies having different health status and the year of collection. Before the bleaching event of 2016, near-coast colonies had higher basal levels of Hsp70 gene and protein compared to back reef colonies. During the bleaching event, the near-coast colonies did not bleach and had significantly higher relative levels of Hsp70 compared to bleached back reef colonies. The A. muricata colonies investigated had genetically identical host genotype and were hosting the same Symbiodiniaceae genus (Symbiodinium) irrespective of habitat and sampling year. These findings provide further evidence of the involvement of Hsp70 in conferring bleaching resistance to corals. Understanding of these processes is paramount for improvement of conservation efforts, where Hsps could potentially be used as proactive biomarkers for heat stress in corals.
\end{abstract}

\section{Hosted file}

Louis et al.,2020_submitted_MEC.doc available at https://authorea.com/users/300651/articles/ 430350-local-acclimatisation-driven-differential-gene-and-protein-expression-patternsof-hsp70-in-acropora-muricata-implications-for-coral-resistance-to-bleaching 